\title{
Spectral properties of the UV absorbing and near-IR reflecting blue pigment, $\mathrm{YIn}_{1-\mathrm{x}} \mathrm{Mn}_{\mathrm{x}} \mathrm{O}_{3}$
}

\author{
Andrew E. Smith ${ }^{\mathrm{a} *}$, Matthew C. Comstock ${ }^{\mathrm{a}}$, and M. A. Subramanian ${ }^{\mathrm{b}}$ \\ ${ }^{a}$ The Shepherd Color Company, 4539 Dues Drive, Cincinnati, Ohio 45246 \\ ${ }^{b}$ Department of Chemistry, Oregon State University, Corvallis, Oregon 97331
}

\section{Graphical Abstract}

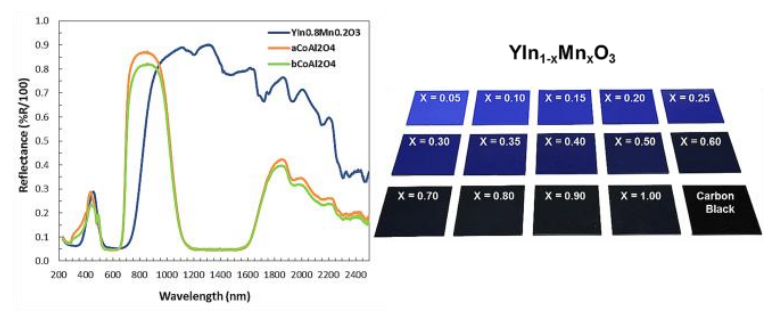

\begin{abstract}
Materials in the full miscibility range of $\mathrm{YlnO}_{3}-\mathrm{YMnO}_{3}$ were prepared and compared to $\mathrm{Cl}$ Pigment Blue $28\left(\mathrm{CoAl}_{2} \mathrm{O}_{4}\right.$ spinel) industrial pigments. The materials were analyzed by XRD, UVVis-NIR spectroscopy, SEM, Laser particle size analysis, and accelerated/outdoor weathering. The optimal composition, $\mathrm{Y}_{0.8} \mathrm{Mn}_{0.2} \mathrm{O}_{3}$, is comparable to standard $\mathrm{CoAl}_{2} \mathrm{O}_{4}$ pigments, for example, having similar CIE color $L^{*}(\sim 34)$ and $b^{*}(\sim-39)$ values, and increased $a^{*}(\sim 10)$ values in an acrylic coating. The potential utility of $\mathrm{Yln}_{0.8} \mathrm{Mn}_{0.2} \mathrm{O}_{3}$ as an industrial pigment was demonstrated by 5000 hours of accelerated QUV weathering $\left(\Delta E^{*}=0.5\right)$ and 48 months of Cincinnati, Ohio outdoor exposure $\left(\Delta \mathrm{E}^{*}=1.1\right)$ in which the performance was comparable or improved compared to $\mathrm{CoAl}_{2} \mathrm{O}_{4}$. The increased UV absorbance measured by thin film absorptivity, and decreased heat buildup determined from PVC spectral properties demonstrate that the $\mathrm{YInO}_{3}-\mathrm{YMnO}_{3}$ materials offer a robust and 'cool' cobalt-free alternative to $\mathrm{CoAl}_{2} \mathrm{O}_{4}$ pigments.
\end{abstract}

\section{Introduction}


Among complex inorganic colored pigments (CICPs), the primary chromophores resulting in blue color are $\mathrm{Co}^{2+}$ and $\mathrm{Cu}^{2+}$. While several other chromophores also yield blue color, $\mathrm{Fe}^{2+} / \mathrm{Fe}^{3+}$, $\mathrm{S}^{3-}, \mathrm{V}^{4+}, \mathrm{Mn}^{5+}, \mathrm{Mn}^{6+}$, and $\mathrm{Ni}^{2+}$, the most stable are the cobalt based pigments having the spinel type structure [1-12]. These include $\mathrm{Co}_{2} \mathrm{SiO}_{4}$ (olivine - spinel like; $\mathrm{Cl}$ Pigment Blue 73), $\mathrm{Co}_{2} \mathrm{SnO}_{4}$ (inverse spinel; $\mathrm{Cl}$ Pigment Blue 35), $\mathrm{CoAl}_{2} \mathrm{O}_{4}$ (spinel; $\mathrm{Cl}$ Pigment Blue 28), and $\mathrm{Co}(\mathrm{Cr}, \mathrm{Al})_{2} \mathrm{O}_{4}$ (spinel; Cl Pigment Blue 36) of which the latter two are preferred due to the intense blue hue, acid/base stability, and lower cost. Despite the superb properties of spinel structured blue pigments, the toxicity of cobalt metal is of concern in the preparation and use of pigments. Current regulations on cobalt metal exposure limits inhalation of dust and particulates to 0.1 $\mathrm{mg} / \mathrm{m}^{3}$ (as Co) 29 - 34\% metal PEL (OSHA) [13]; however, modern precautionary equipment and strict monitoring have made working with cobalt and cobalt oxides safe. Several cobalt based spinel blue pigments have received FDA approval for specific applications suggesting the material is quite robust. Notwithstanding, concerns related to safe handling have prompted a search for alternative cobalt-free blue colorants.

The solar irradiance incident on the surface of the Earth can be divided into three weighted regions; 5\% ultraviolet (UV, 290-380nm), 43\% visible (VIS, 380-720nm), and 52\% infrared (IR, 720-2500nm), Figure 1 [14]. The way that pigmented coatings interact with this energy can affect long term performance. Pigments that absorb in the UV may help limit or delay binder degradation. Absorption of solar energy can lead to heat buildup that can result in premature weathering and warping. In general, light-colored pigmented coatings tend to have lower heat buildup than dark-colored coatings as a result of higher solar reflectance. Some dark-colored 
pigmented systems are highly absorbing in the visible region, yet weakly absorbing and highly scattering in the near infrared region. A system of this sort can provide dark shades with low heat buildup compared to pigment systems that absorb across a broader wavelength range.

Roofing and exterior architectural applications require materials with high durability, weatherability, and temperature stability. White opaque surfaces, generally rutile $\mathrm{TiO}_{2}$ based, are often preferred for flat or low slope roofing systems as they reflect the most visible and IR radiation which results in reduced heat buildup (HBU). The reduction in HBU, while slowing binder degradation, can also improve energy efficiency by means of reduced convection and conduction about the roof. This results in reduced air conditioning energy costs during peak energy consumption months such as in the summer and fall [15]. Advances in the fundamental knowledge of pigment technology have allowed for the use of a variety of colors to be used as cost effective means to reduce energy consumption and improve product life. $\mathrm{CoAl}_{2} \mathrm{O}_{4}$ and $\mathrm{Co}(\mathrm{Al}, \mathrm{Cr})_{2} \mathrm{O}_{4}$ spinel blues exhibit reasonably high UV opacity which contributes to their effective weathering in exterior coatings and plastics. Nevertheless, a relatively large $\mathrm{Co}^{2+}$ absorption band in the near-IR limits the solar reflectance and thus contributes to overall heat build-up. Suitable alternatives, with similar color and performance as $\mathrm{CoAl}_{2} \mathrm{O}_{4}$, do not exist, or have not been reported at this point.

Recently, $\mathrm{Mn}^{3+}$ was shown to be a blue chromophore when occupying the trigonal bipyramidal site of $\mathrm{In}^{3+}$ in the hexagonal oxide $\mathrm{YlnO}_{3}$ [16]. The unique structure allows for metal specific apical bond distances of $\mathrm{Mn}$ and $\mathrm{In}$ which results in a systematic progression of color upon 
increasing $\mathrm{Mn}^{3+}$ concentration. An intense blue color is observed over much of the miscibility range. Interestingly, few reports have addressed the material properties in terms of industrial pigment utility $[17,18]$, and such reports are based on solution methods. In this paper, we evaluate the hitherto unknown industrial performance of the full miscibility range of $\mathrm{Yln}_{1}$ ${ }_{x} \mathrm{Mn}_{\mathrm{x}} \mathrm{O}_{3}$ pigments by comparing the color coordinates, UV and IR reflectance, and accelerated and outdoor weathering with that of existing spinel structured (Cl Pigment Blue 28) industrial blue pigments prepared using traditional syntheses.

\section{Experimental}

\subsection{Synthesis}

Fourteen compositions within the $\mathrm{YnO}_{3}-\mathrm{YMnO}_{3}$ solid solution were prepared by conventional solid state ceramic methods: a stoichiometric mixture of $\mathrm{Y}_{2} \mathrm{O}_{3}$ (H.C. Starck Grade A-99.9\%+), $\mathrm{In}_{2} \mathrm{O}_{3}$ (Indium Corp. Grade B Fine-99.99\%), and $\mathrm{Mn}_{3} \mathrm{O}_{4}$ (Chemalloy) was intimately blended and calcined in ceramic crucibles at temperatures from $1150{ }^{\circ} \mathrm{C}$ to $1300{ }^{\circ} \mathrm{C}$ for 6 hours in a muffle furnace. The resulting product was screened and milled as an aqueous slurry on a paint shaker for 300 minutes using deionized water, and $0.4-0.7 \mathrm{~mm}$ Yttria stabilized $\mathrm{ZrO}_{2}$ media in a water/pigment/media ratio of $2: 1: 4$.

\subsection{Method of pigmentation}

Acrylic-based coatings were prepared utilizing milled pigment compositions. An acrylic enamel blend (called a grind) was prepared by blending 50\%/weight acrylic enamel (PPG Delstar DMR 499) and $50 \% /$ weight xylene. The blend was then added to a cup with glass beads and pigment 
in a ratio of $1.4: 3.2: 1$ respectively, and ground in a Speed Mixer ${ }^{\mathrm{TM}}$ at 3500rpm for 5 minutes. The masstone mixture was then prepared by combining an aliquot of the grind and acrylic enamel (DMR 499) in a 2.165:1 ratio and mixing on a Speed Mixer ${ }^{\mathrm{T} M}$ at 3500rpm for 1 minute. The tint was prepared by combining an aliquot of the grind and white base (PPG Delstar DMR 400 ) in a ratio of $1: 3.7$ mixing on a Speed Mixer ${ }^{\mathrm{T} M}$ at $3500 \mathrm{rpm}$ for 1 minute. The resulting masstone and tint mixtures were drawn on a Leneta card using a 15-mil precision wet film applicator. The wet coating was then dried in air for 30 minutes and placed in an oven at 60 - 70 ${ }^{\circ} \mathrm{C}$ for 1 hour.

PVDF (polyvinylidene difluoride) thin films were prepared using a mixture of isophorone, Solvay Plastics Hylar ${ }^{\circledast} 5000$ PVDF resin, and pigment in a ratio of $35: 19: 1$ respectively. After homogenization, the mixture was then drawn on a glass plate using a precision wet film applicator. A 4-mil, 6-mil, and 8-mil gage was used to prepare films of each composition and two different standards. The films were dried in an oven at $232{ }^{\circ} \mathrm{C}$, allowed to cool to room temperature, and then cut into 2 inch $\times 2$ inch squares. The thickness of each film was measured using a micrometer. Approximate film thicknesses of $\sim 12 \mu \mathrm{m}, \sim 20 \mu \mathrm{m}$, and $\sim 28 \mu \mathrm{m}$ were observed.

PVC (Polyvinyl Chloride) press outs were prepared by homogenizing a mixture of pigment and Natural PVC compound in a ratio of $1: 21$ respectively. The mixture is then preheated and further homogenized in a 2-roll milled heated to $205{ }^{\circ} \mathrm{C}$. The final sheet is cooled to room temperature. Sections of the sheet are then cut and placed onto a Carver press preheated to 
$177^{\circ} \mathrm{C}$, and pressed under 6500 psi for 3 minutes. The resulting pressed panels had a thickness of $\sim 1.5-1.75 \mathrm{~mm}$ and were cut to $76 \mathrm{~mm} \times 76 \mathrm{~mm}$ squares according to ASTM D4803-97 [19].

\subsection{Characterization techniques}

Phase purity of the synthesized materials was characterized by X-ray powder diffraction (XRD) patterns collected on a Rigaku DMax 2100T using CuKa radiation. The applied tube energy was $40 \mathrm{kV}$ and $40 \mathrm{~mA}$ and the optics used a traditional parafocusing beam configuration. All samples were analyzed with step scans from $10-90^{\circ} 2 \Theta$ at $1^{\circ} / \mathrm{min}$ and $0.01 \%$ step. Jade software (Rigaku) was used to index the powder patterns to phases within the ICSD/JCPDS database.

The particle size distribution of milled material was analyzed using a Horiba LA900 Laser Particle Size Analyzer on the basis of Mie scattering theory. The suspension was stabilized by the addition of two drops of Dow Tamol SG-1 dispersant and then homogenized for three minutes by ultra-sonication.

SEM (scanning electron microscopy) images were obtained using a FEl/Philips Field Emission SEM model XL 30 . Prior to the SEM characterization, the powder samples were coated with a Au-Pd layer (thickness ca. $30 \mathrm{~nm}$ ). The SEM images were collected using the following settings: High tension of $30 \mathrm{kV}$ and a working distance of $10 \mathrm{~mm}$. Images were obtained of samples before and after media milling. 
Optical measurements were performed on a PerkinElmer Lambda 900 spectrophotometer utilizing a $150 \mathrm{~mm}$ integrating sphere with a Spectralon ${ }^{\circledR}$ reference. Samples were analyzed from $230-2500 \mathrm{~nm}$ at $0.08 \mathrm{sec} / \mathrm{nm}$ yielding an integration speed of $750 \mathrm{~nm} / \mathrm{min}$. Spectra were collected in \%R (reflectance) mode for both 15-mil Acrylic coatings on Leneta cards and pressed PVC panels. Transmission spectra were obtained for thin films placed in the internal transmission port of the reflectance sphere. Transmittance was then converted to Absorbance.

Color coordinates were determined from reflectance spectra using PerkinElmer Color Module ver. 3.00. Solar reflectance values were calculated as described in ASTM method E903-12 using a weighted ordinate method [20]. In the CIE color coordinate system, $L^{*}$ or lightness, refers to a numerical scale from $0-100$ where 0 is black and 100 is white. Red and green colors are defined as a (+) and (-) $a^{*}$ value respectively, and blue and yellow colors are defined as (+) and $(-) b^{*}$ value respectively. Chroma, $C^{*}$, represents the saturation of a color and is quantified as $C^{*}=\left[\left(a^{*}\right)^{2}+\left(b^{*}\right)^{2}\right]^{1 / 2}$. The hue angle, $h^{\circ}$, represents the angle on a circular axis where the color ranges from $0^{\circ}$ (red) through $90^{\circ}$ (yellow), $180^{\circ}$ (green), $270^{\circ}$ (blue) and back to $0^{\circ}$. A common measurement for the 'distance' between two color parameters is the delta parameter, $\Delta \mathrm{L}^{*}$, $\Delta \mathrm{a}^{*}$, and $\Delta \mathrm{b}^{*}$. The $\Delta \mathrm{E}^{*}$ parameter is a measurement of the distance between two colors which is calculated as $\Delta \mathrm{E}^{*}=\left[\left(\Delta \mathrm{L}^{*}\right)^{2}+\left(\Delta \mathrm{a}^{*}\right)^{2}+\left(\Delta \mathrm{b}^{*}\right)^{2}\right]^{1 / 2}$.

Gloss measurements were performed using a Byk - Gardner Co. Micro-TRI-gloss instrument. The instrument is calibrated using a black glass standard with an index of refraction of 1.567 . 
Depending on the gloss value at $60^{\circ}$, the proper angle of incidence may be $20^{\circ}, 60^{\circ}$, or $85^{\circ}$. Semi-gloss surfaces generally range from $10-70$ units at $60^{\circ}$. Highly reflective surfaces are measured at $20^{\circ}$, and matte surfaces are measured at $85^{\circ}$.

\section{Results and Discussion}

\subsection{Phase and morphology}

Precursor oxides for several compositions within the $\mathrm{YlnO}_{3}-\mathrm{YMnO}_{3}$ miscibility range were initially fired at temperatures from $1150{ }^{\circ} \mathrm{C}$ to $1300{ }^{\circ} \mathrm{C}$ for 6 hours to establish the optimal firing conditions to prepare phase pure materials. All compositions were found to form the hexagonal type structure after a single calcination at $1288{ }^{\circ} \mathrm{C}$ for 6 hours. Figure 2 depicts the $\mathrm{X}$-ray powder diffraction patterns for the full miscibility range investigated. All of the diffraction peaks can be indexed to the hexagonal structure of $\mathrm{YMnO}_{3}$ (JCPDS NO: 25-1079) having the $\mathrm{P}_{3} \mathrm{~cm}$ space group, or $\mathrm{YInO}_{3}$ (JCPDS NO: 70-0133) having the $\mathrm{P}_{3} \mathrm{~cm}$ space group. No impurity peaks were evident. The inset of Figure 2 shows a magnified view of the (002) and (102) reflections showing the intensity increase and $2 \Theta$ shift with Mn substitution. Lattice parameters and unit cell volumes of the solid solution decreased with increasing $M n$ concentration, and are consistent with values reported previously where $X=0.2$ in $\mathrm{Yin}_{1-\mathrm{x}} \mathrm{Mn}_{\mathrm{x}} \mathrm{O}_{3}$ is previously reported to be $a=6.24 \AA$ and $c=12.05 \AA$, and is found to be $a=6.26 \AA$ and $c=12.07 \AA$ in this work [16].

The $a$-parameter decreases slightly while the $c$ parameter decreases significantly upon $\mathrm{Mn}^{3+}$ addition to the lattice. This is consistent with the size variation between ionic radii of $\mathrm{Mn}^{3+}$ and $\ln ^{3+}$, and the corresponding effect on the apical bond distances [16, 21]. 
As-fired samples across the solid solution exhibited mean particle size diameters in the range of $9.45-10.69 \mu \mathrm{m}$. Standard pigment applications in coatings and plastics generally require the mean particle size diameter of $\sim 1.0 \mu \mathrm{m}$ for ease of dispersion. Therefore, each sample was media-milled to a mean diameter of $0.88+/-0.03 \mu \mathrm{m}$. Figure 3 illustrates the particle size distribution curves based on intensity for the full range of materials after media milling. These values are consistent with current commercial $\mathrm{CoAl}_{2} \mathrm{O}_{4}$ blue pigments which range from 0.6 $1.1 \mu \mathrm{m}$ mean diameter and have a mono-modal distribution.

Figure 4 shows the morphology of pre-milled and post-milled materials for select compositions by SEM. Previously, it was shown that a spherical morphology could be obtained through pyrolysis of aerosols [17], and irregular and granular morphology could be obtained through sol-gel combustion techniques [18]; however, no details have been reported on particle morphology for traditional solid state syntheses. Interestingly, each composition appears to form large hexagon and plate-like, fused agglomerates. The fused agglomerates for all compositions appear similar in size distributions. After media milling, the particles are irregular in morphology and are again similar in size as confirmed by laser particle size analysis.

\subsection{Spectral behavior}

\subsubsection{Visible (VIS)}

Figure 5 shows the approximate orbital splitting for both tetrahedral $\left(T_{d}\right)$ and trigonal bipyramidal (TBP) coordination environments with reference to the free ion, and $\mathrm{O}_{\mathrm{h}}$. In the spinel-type structure, $\mathrm{Co}^{2+}\left(3 d^{7}\right)$ may occupy a $T_{d}$ coordination for which there are three spin 
allowed transitions, or an octahedral $\left(\mathrm{O}_{h}\right)$ coordination environment for which there are three spin-forbidden transitions. In the ideal $\mathrm{CoAl}_{2} \mathrm{O}_{4}$ spinel pigment, however, $\mathrm{Co}^{2+}$ is found to occupy the $\mathrm{T}_{d}$ coordination environment. For $\mathrm{Co}^{2+}$ the quartet ${ }^{4} \mathrm{~F}$ ground state is split into two spin-orbit levels increasing in energy from $\boldsymbol{e}$ (doubly degenerate) to $\boldsymbol{t}_{\mathbf{2}}$ (triply degenerate) in a

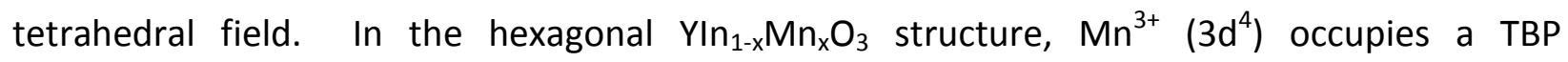
coordination environment for which there are two spin-allowed transitions. For $\mathrm{Mn}^{3+}$, the quintet ground state term ${ }^{5} \mathrm{D}$ is split into three spin-orbit levels increasing in energy from $e^{\prime \prime}$ (doubly degenerate) $<\boldsymbol{e}$ (doubly degenerate) $<\boldsymbol{a}$ in a trigonal bipyramidal field. In Figure 6 the approximated absorbance spectra calculated from diffuse reflectance values by the KubelkaMunk remission function, $f(R)=(1-R)^{2} / 2 R$, are presented [22]. As described, the spin-allowed transitions are observed in the visible spectrum as three distinct absorption bands for $\mathrm{T}_{d} \mathrm{Co}^{2+}$ in $\mathrm{CoAl}_{2} \mathrm{O}_{4}$ (Figure 6 bottom) and two distinct absorption bands for TBP $\mathrm{Mn}^{3+}$ in $\mathrm{YMn}_{0.2} \mathrm{In}_{0.8} \mathrm{O}_{3}$ (Figure 5 top). In both cases, the absorptions in the visible spectrum occur over the entire red, orange, yellow, and green regions between 500 and $700 \mathrm{~nm}$. Absence of strong absorption bands between $400-500 \mathrm{~nm}$ results in a pure blue color being reflected. It should be noted that the spectra provided for commercial $\mathrm{CoAl}_{2} \mathrm{O}_{4}$ do exhibit weak absorption peaks at $\sim 405$ $\mathrm{nm}, 450 \mathrm{~nm}$, and $480 \mathrm{~nm}$. These absorptions have been attributed to spin-forbidden transitions of $\mathrm{O}_{\mathrm{h}} \mathrm{Co}^{2+}$, or spin-allowed transitions of $\mathrm{O}_{\mathrm{h}} \mathrm{Co}^{3+}[23]$.

The impact of weak absorption shifts on the color can be significant when considering variation in the $\mathrm{a}^{*}$ (red) value for blue shade materials. Table 1 provides the CIE LabCh color values and VIS absorption band minima for the full $\mathrm{Y}_{1-\mathrm{x}} \mathrm{Mn}_{\mathrm{x}} \mathrm{O}_{3}$ solid solution and $\mathrm{CoAl}_{2} \mathrm{O}_{4}$ commercial 
pigments. Compositions with low $\mathrm{Mn}$ concentration result in a distinct and sharp absorption band in the $300-400 \mathrm{~nm}$ region and $500-800 \mathrm{~nm}$ region, Figure 6 . The absence of absorption from 400 - $500 \mathrm{~nm}$ (absorption minima) for lower Mn concentration results in bright blue hues. This is observed for compositions of $0.05<\mathrm{x}<0.5$ in $\mathrm{Yln}_{1-\mathrm{x}} \mathrm{Mn}_{\mathrm{x}} \mathrm{O}_{3}$. However, as the $\mathrm{Mn}$ concentration increases, the doublet absorption band centered at $\sim 600 \mathrm{~nm}$ broadens and intensifies which yields overlap with the absorption band at $350 \mathrm{~nm}$ subsequently absorbing intermediately in the $400-500 \mathrm{~nm}$ range. The result of this overlap is a progressive decrease in the blue color as well as a decrease in lightness, Table 1 . The materials with highest manganese content appear blue-black. This progression in both color and the absorption band center seems to be due to the structural effects caused by size differences between $\mathrm{Mn}^{3+}$ and $\mathrm{In}^{3+}$ in TBP coordination as well as the concentration effects on the orbital splitting energies, Figure 5 and Table $1[16,21]$. Representative $\mathrm{CIE}$ color coordinates for traditional $\mathrm{CoAl}_{2} \mathrm{O}_{4}$ spinel pigments are $L^{*}=33, a^{*}=7, b^{*}=-35$. The blue color of the $\mathrm{Y}_{1-\mathrm{x}} \mathrm{Mn}_{\mathrm{x}} \mathrm{O}_{3}$ system varies widely depending on Mn concentration and shows its versatility in color formulation as compositional tuning allows for color control. For $\mathrm{YIn}_{0.8} \mathrm{Mn}_{0.2} \mathrm{O}_{3}, \mathrm{CIE}$ color coordinates are $\mathrm{L}^{*}=35, \mathrm{a}^{*}=10, \mathrm{~b}^{*}=$ -39 which is red-toned, blue, and about as dark as $\mathrm{CoAl}_{2} \mathrm{O}_{4}$, Table 1. These two pigments having different structures, chromophores, and optical transitions are remarkably similar in color.

\subsubsection{Ultraviolet (UV)}

Absorption of UV energy can cleave chemical bonds and cause polymer degradation. UV stabilizers are commonly added to plastic resin systems to suppress photo-degradation, but pigments that absorb in the UV region can function effectively in the same manner [24]. The UV 
absorption spectra for $\mathrm{YIn}_{1-\mathrm{x}} \mathrm{Mn}_{\mathrm{x}} \mathrm{O}_{3}$ and $\mathrm{CoAl}_{2} \mathrm{O}_{4}$ pigments were obtained by dispersion in thin films of PVDF (polyvinylidene difluoride). The relative thin-film absorptivity of the $\mathrm{Y}_{1} \mathrm{n}_{1-\mathrm{x}} \mathrm{Mn}_{\mathrm{x}} \mathrm{O}_{3}$ pigments is higher than that for $\mathrm{CoAl}_{2} \mathrm{O}_{4}$ across the UV region, Figure 7. The improved UV absorptivity of $\mathrm{Yln}_{1-\mathrm{x}} \mathrm{Mn}_{\mathrm{x}} \mathrm{O}_{3}$ suggests that these materials will likely provide greater protection than $\mathrm{CoAl}_{2} \mathrm{O}_{4}$ pigments against UV-induced photo-degradation. This inference was tested, in part, through natural and accelerated weathering trials.

In addition to testing the potential photo-stabilization effects of a pigment, natural outdoor weathering and accelerated UV weathering also evaluates the effects of other variables such as humidity, heat, and temperature in cycles. Weathering results are presented in Table 2. After 5000 hours of continuous accelerated UV exposure the $\mathrm{YIn}_{1-\mathrm{x}} \mathrm{Mn}_{\mathrm{x}} \mathrm{O}_{3}$ pigmented panels changed by less than $\Delta E^{*}=0.5$ units. After 48 months of outdoor weathering the $\mathrm{Y}_{1-\mathrm{x}} \mathrm{Mn}_{\mathrm{x}} \mathrm{O}_{3}$ pigmented panels changed color by less than $\Delta \mathrm{E}^{*}=1.4$ units. These weathering results compare well with those for standard $\mathrm{CoAl}_{2} \mathrm{O}_{4}$ pigmented panels shown in the Table 2 for comparison. The small changes in $\Delta \mathrm{E}^{*}$ indicate minimal color shifts which we attribute to a lowering of the gloss value due to exposure. $\mathrm{Y}_{1-\mathrm{x}} \mathrm{Mn}_{\mathrm{x}} \mathrm{O}_{3}$ pigments are durable, light-fast, and stable to changing conditions and appear to be a potential replacement for $\mathrm{CoAl}_{2} \mathrm{O}_{4}$ based pigments.

\subsubsection{Near-Infrared (NIR)}

The near infrared (NIR) region of the solar spectrum accounts for $\sim 52 \%$ of incident solar energy, Figure 1. This energy, if absorbed in addition to UV and Vis energy, can result in heat build-up which can have negative effects on both the resin system and the immediate surrounding 
environment. In architectural coatings, lighter colors are frequently used to reduce the total solar energy absorbed. By nature, darker materials tend to absorb more energy than lighter materials. For instance, carbon black absorbs $\sim 95 \%$ of solar energy, whereas $\mathrm{TiO}_{2}$ absorbs less than $\sim 25 \%$. Optimizing the NIR spectral character of pigments can improve heat build-up issues with dark colors leading to improved resign performance, reduced warping, and reduced cooling costs in some cases.

Figures 8 and 9 depict the full reflectance spectra of two $\mathrm{CoAl}_{2} \mathrm{O}_{4}$ pigments and the full $\mathrm{YIn}_{1}$ ${ }_{x} \mathrm{Mn}_{x} \mathrm{O}_{3}$ solid solution in acrylic resin. Cobalt based pigments are readily identified in the NIR spectral region by a large absorption band between $1200 \mathrm{~nm}$ and $1600 \mathrm{~nm}$, Figure 9 . In contrast, $\mathrm{YIn}_{1-\mathrm{x}} \mathrm{Mn}_{\mathrm{x}} \mathrm{O}_{3}$ materials do not exhibit any strong absorptions in the near infrared, and instead, scatter light with high reflectance (small distinct absorptions in the NIR that occur at $1400 \mathrm{~nm}, 1700 \mathrm{~nm}, 1900 \mathrm{~nm}, 2100 \mathrm{~nm}$, and $2300-2500 \mathrm{~nm}$ are due to the acrylic resin), Figure 8 and 9. Total Solar Reflectance (TSR) is a measure of the incident solar energy reflected by a surface. ${ }^{10}$ More accurately, it is the solar-irradiance weighted average of a reflectance spectrum. It can also be useful to calculate related energy-weighted reflectance values in the specific UV, Vis, and NIR regions. Table 3 lists the TSR and the percent reflectance in the different spectral regions for the $\mathrm{Yln}_{1-x} \mathrm{Mn}_{x} \mathrm{O}_{3}$ materials alongside those for $\mathrm{CoAl}_{2} \mathrm{O}_{4}$. The $\mathrm{Yln}_{1-}$ ${ }_{x} \mathrm{Mn}_{x} \mathrm{O}_{3}$ materials have higher TSR values than the $\mathrm{CoAl}_{2} \mathrm{O}_{4}$ products listed, in large part because they reflect more of the incident NIR energy. 
Theoretical heat buildup values, as described by Peake and Sullivan, were calculated from Reflectance spectra obtained on pigmented PVC panels as an alternative to ASTM D4803-97 $[19,25]$. Table 4 lists the calculated $\mathrm{HBU}$ temperatures of the $\mathrm{Yln}_{1-\mathrm{x}} \mathrm{Mn}_{\mathrm{x}} \mathrm{O}_{3}$ materials as well as carbon black and other materials reported by Peake and Sullivan. The HBU temperatures for the $\mathrm{Yln}_{1-\mathrm{x}} \mathrm{Mn}_{\mathrm{x}} \mathrm{O}_{3}$ materials range from 27 to $30^{\circ} \mathrm{C}$ as compared to temperatures near $37^{\circ} \mathrm{C}$ for $\mathrm{CoAl}{ }_{2} \mathrm{O}_{4}$ pigments and $42^{\circ} \mathrm{C}$ for carbon black. PVC pigmented with $\mathrm{Y}_{1-\mathrm{x}} \mathrm{Mn}_{\mathrm{x}} \mathrm{O}_{3}$ materials will not experience the higher HBU temperatures calculated for cobalt based blues and other NIR absorbing materials. The difference of $7-10^{\circ} \mathrm{C}$ cooler indicates that over the lifetime of a pigmented PVC panel, $Y \mathrm{In}_{1-\mathrm{x}} \mathrm{Mn}_{\mathrm{x}} \mathrm{O}_{3}$ materials will result in the panel being exposed to lower temperature variation and thus have reduced potential to warp and degrade.

\section{Conclusion}

Samples across the full composition range $\mathrm{Y}_{1-\mathrm{x}} \mathrm{Mn}_{\mathrm{x}} \mathrm{O}_{3}, \mathrm{x}=0.05$ to 1 , were prepared and compared to established industrial pigments. In some markets and applications, the $\mathrm{Cr}$, $\mathrm{Co}$, and $\mathrm{Ni}$-free nature of this system is an attractive alternative to current blue pigments. A diverse blue color range is observed across the solid solution. The $x=0.2$ composition, $\mathrm{Y}_{0.8} \mathrm{Mn}_{0.2} \mathrm{O}_{3}$, is similar to standard $\mathrm{CoAl}_{2} \mathrm{O}_{4}$ pigments, having similar $\mathrm{L}^{*}$ and $\mathrm{b}^{*}$ values, and increased $\mathrm{a}^{*}$ (red) values. To optimize the color, compositions of $0.17<x<0.23$ should be investigated further. The increased UV absorbance, stability in QUV and outdoor weathering tests, and low HBU temperature values demonstrate that the $\mathrm{Y}_{1-\mathrm{x}} \mathrm{Mn}_{\mathrm{x}} \mathrm{O}_{3}$ materials offer a robust alternative to $\mathrm{CoAl}_{2} \mathrm{O}_{4}$ pigments. In addition, with high TSR and low $\mathrm{HBU}$, this system provides a 'cool pigment' for use in a variety of exterior applications, reducing surface temperatures, compared 
to similarly colored $\mathrm{CoAl}_{2} \mathrm{O}_{4}$ pigments, which could have beneficial impact on cooling costs and energy consumption.

\section{Acknowledgements}

The authors extend their thanks to Ms. Linda Branam for help with thin film preparation, Mr. Greg Allie for help with weathering and QUV preparation, and Ms. Christen Riedl for PVC preparation. We also thank Dr. Pablo Rosales at the University of Cincinnati for SEM images. The work performed at Oregon State University is supported by NSF grant, DMR 1508527.

\section{References}

1. Llusar M, Fores A, Badenes JA, Calbo J, Tena MA, Monros G. Colour analysis of some cobalt-based blue pigments. J Eur Ceram Soc 21 (2001) 1121-1130.

2. Llusar M, Zielinska A, Tena MA, Badenes JA, Monros G. Blue-violet ceramic pigments based on Co and Mg Co2-xMgxP2O7 diphosphates. J Eur Ceram Soc 30 (2010) 18871896.

3. Taran MN, Koch-Müller M, Feenstra A. Optical spectroscopic study of tetrahedrally coordinated Co2+ in natural spinel and staurolite at different temperatures and pressures. American Mineralogist 94(11-12) (2009) 1647-1652.

4. Kendrick E, Kirk CJ, Dann SE. Structure and colour properties in the Egyptian Blue Family, $M 1-x M^{\prime} x C u S i 4010$, as a function of $M, M^{\prime}$ where $M, M^{\prime}=C a, S r$ and Ba. Dyes Pigments 73 (2007) 13-18. 
5. Pozza G, Ajo D, Chiari G, De Zuane F, Favaro M. Photoluminescence of the inorganic pigments Egyptian blue, Han blue and Han purple. J Cult Heritage 1 (2000) 393-398.

6. Frost RL, Martens WN, Rintoul L, Mahmutagic E, Kloprogge JT. Raman spectroscopic study of azurite and malachite at 298 and 77K. J Raman Spec 33(4) (2002) 252-259.

7. Samain L, Grandjean F, Long GJ, Martinetto P, Bordet P, Strivay D. Relationship between the Synthesis of Prussian Blue Pigments, their Color, Physical Properties, and their Behavior in Paint Layers. J Phys Chem C 117(19) (2013) 9693-9712.

8. Booth DG, Dann SE, Weller MT. The effect of the cation composition on the synthesis and properties of ultramarine blue. Dyes Pigments 58 (2003) 73-82.

9. Trojan M. Synthesis of a Green-Blue Zirconium Silicate Pigment. Dyes Pigments 14 (1990) 9-22.

10. Eastaugh N, Walsh V, Chaplin T, Siddall R. Pigment compendium: A dictionary and optical microscopy of historical pigments. Amsterdam: Butterworth-Heinemann, (2008) 37-38.

11. Costa G, Ribeiro MJ, Hajjaji W, Seabra MP, Labrincha JA, Dondi M, Cruciani G. Ni-doped hibonite (CaAl12O19): A new turquoise blue ceramic pigment. J Eur Ceram Soc 29(13) (2009) 2671-2678.

12. Reinen D, Lachwa H, Allmann R. Colour and Constitution for Mnv in Tetrahedral Oxygen Coordination. I. An EPR and Ligand Field Spectroscopic Investigation of Mnv in Apatite Phases and the Structure of Ba5(MnO4)3Cl. Z Anorg Allg Chem 542 (1986) 71-88. 
13. United States Department of Labor: Occupational Safety \& Health Administration. Web. https://www.osha.gov/dts/chemicalsampling/data/CH_229100.html. Accessed March 8, 2015.

14. ASTM G173-03 (2012). Standard Tables for Reference Solar Spectral Irradiances: Direct Normal and Hemispherical on $37^{\circ}$ Tilted Surface, ASTM International, West Conshohocken, PA, 2012, www.astm.org.

15. Levinson R, Akbari H, and Reilly JC. Cooler tile-roofed buildings with near-infraredreflective non-white coatings. Build Environ 42 (2007) 2591-2605.

16. Smith AE, Mizoguchi H, Delaney K, Spaldin NA, Sleight AW, Subramanian MA. Mn3+ in trigonal bipyramidal coordination: a new blue chromophore. J Amer Chem Soc 131 (2009) 17084-17086.

17. Ocana M, Espinos JP, Carda JB. Synthesis, through pyrolysis of aerosols, of YIn1-xMnxO3 blue pigments and their efficiency for colouring glazes. Dyes Pigments 91 (2011) 501-7.

18. Jose S, Jayaprakash A, Laha S, Natarajan S, Nishanth KG, Reddy MLP. YIn0.9Mn0.103ZnO nano-pigment exhibiting intense blue color with impressive solar reflectance. Dyes Pigments 124 (2016) 120-129.

19. ASTM D4803-97 (2002). Standard Test Method for Predicting Heat Buildup in PVC Building Products, ASTM designation: D4803-97 (2002), American Society of Testing and Materials, Philadelphia.

20. ASTM E903-12 (2012). Standard Test Method for Solar Absorptance, Reflectance, and Transmittance of Materials Using Integrating Spheres, ASTM International, West Conshohocken, PA, 2012, www.astm.org. 
21. Shannon RD. Revised effective ionic radii and systematic studies of interatomic distances in halides and chalcogenides. Acta Cryst A32 (1976) 751-767.

22. Kubelka P., and Munk, F. Ein beitrag zur optik der farbanstriche. Z. tech. Phys. 12 (1931) 593-601.

23. De Souza LKC, Zamian JR, De Rocha Filho GN, Soledade LEB, Dos Santos IMG, Souza AG, Scheller T, Angelica RS, Da Costa CEF. Blue Pigments Based on CoxZn1-xAl2O4 Spinels Synthesized by the Polymeric Precursor Method. Dyes Pigments 81 (2009) 187-192.

24. Allen, N., Edge, E. Fundamentals of Polymer Degradation and Stabilization. Springer Science \& Business Media, Oct 31, 1992. P75-95.

25. Sullivan T, Peake G. Use of reflectance spectra to predict heat buildup of pigmented PVC panels. J Vinyl Tech 15(4) (1993) 232-236. 


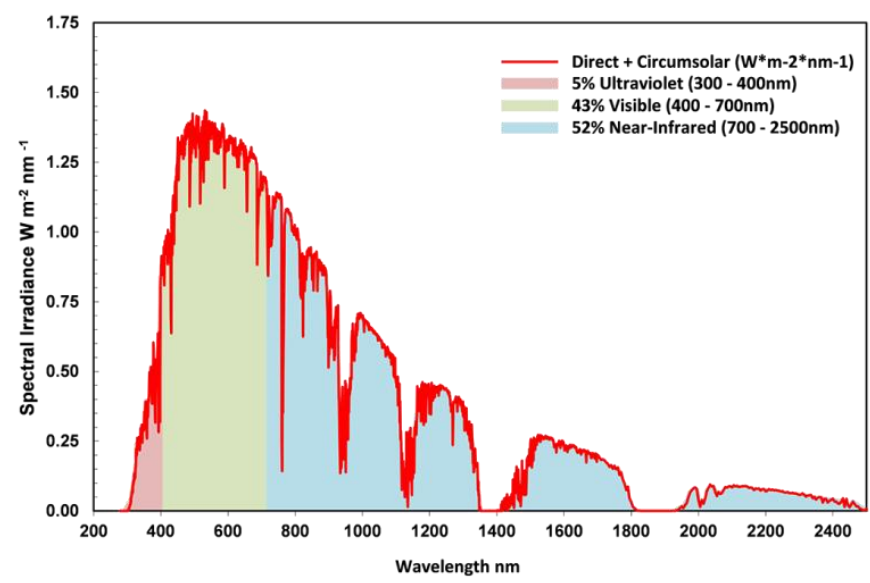

Figure 1. Solar spectral irradiance based on combined direct and circumsolar effects from ASTM G173-03 reference spectra derived from the Simple Model of the Atmospheric Radiative Transfer of Sunshine, SMARTS [14]. Shading of spectral regions has been added. 


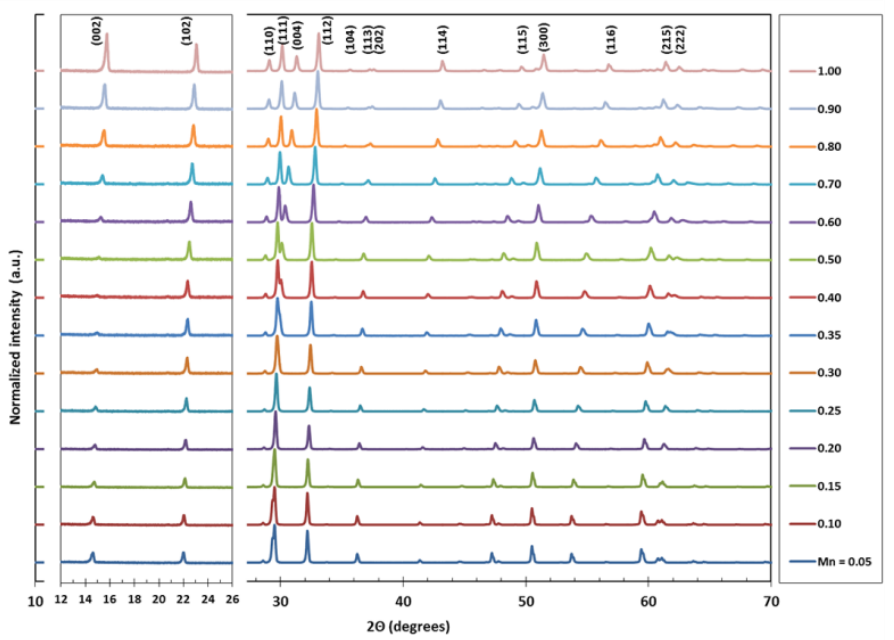

Figure 2. Normalized powder x-ray diffraction patterns of the $\mathrm{YInO}_{3}-\mathrm{YMnO}_{3}$ miscibility range. The inset shows the (002) and (102) peaks magnified. 


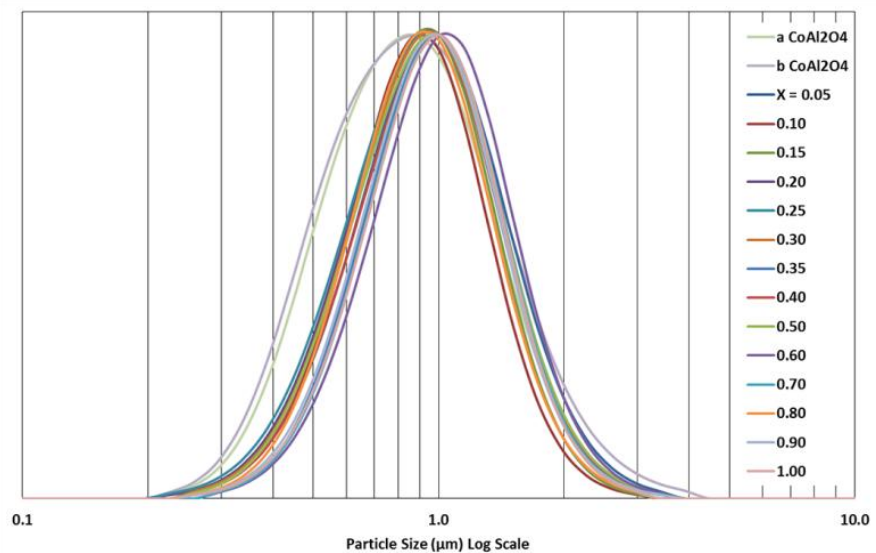

Figure 3. Normalized particle size distribution of $\mathrm{YIn}_{1-x} \mathrm{Mn}_{x} \mathrm{O}_{3}, x=0.05-1.0$, and commercial $\mathrm{CoAl}{ }_{2} \mathrm{O}_{4}$ pigments. 


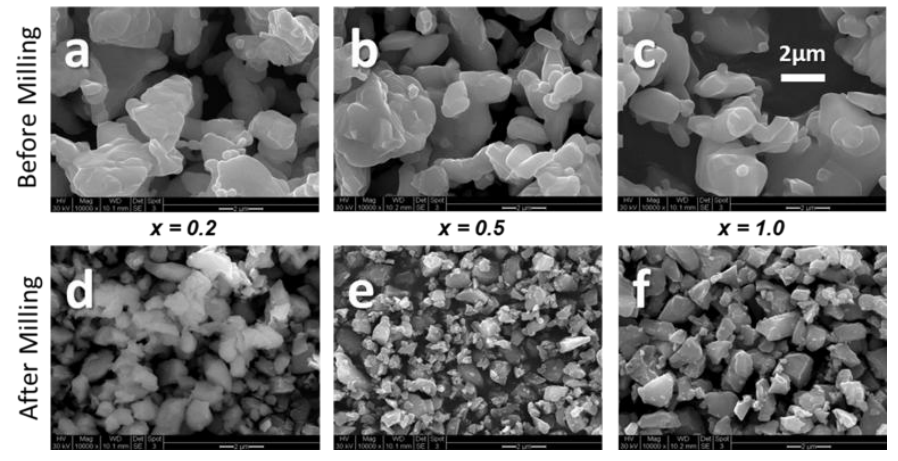

Figure 4. SEM images of $Y I n_{1-x} M n_{x} O_{3}$, before (a-c) and after $(d-f)$ milling where $x=0.2,0.5$, and 1.0, respectively. 


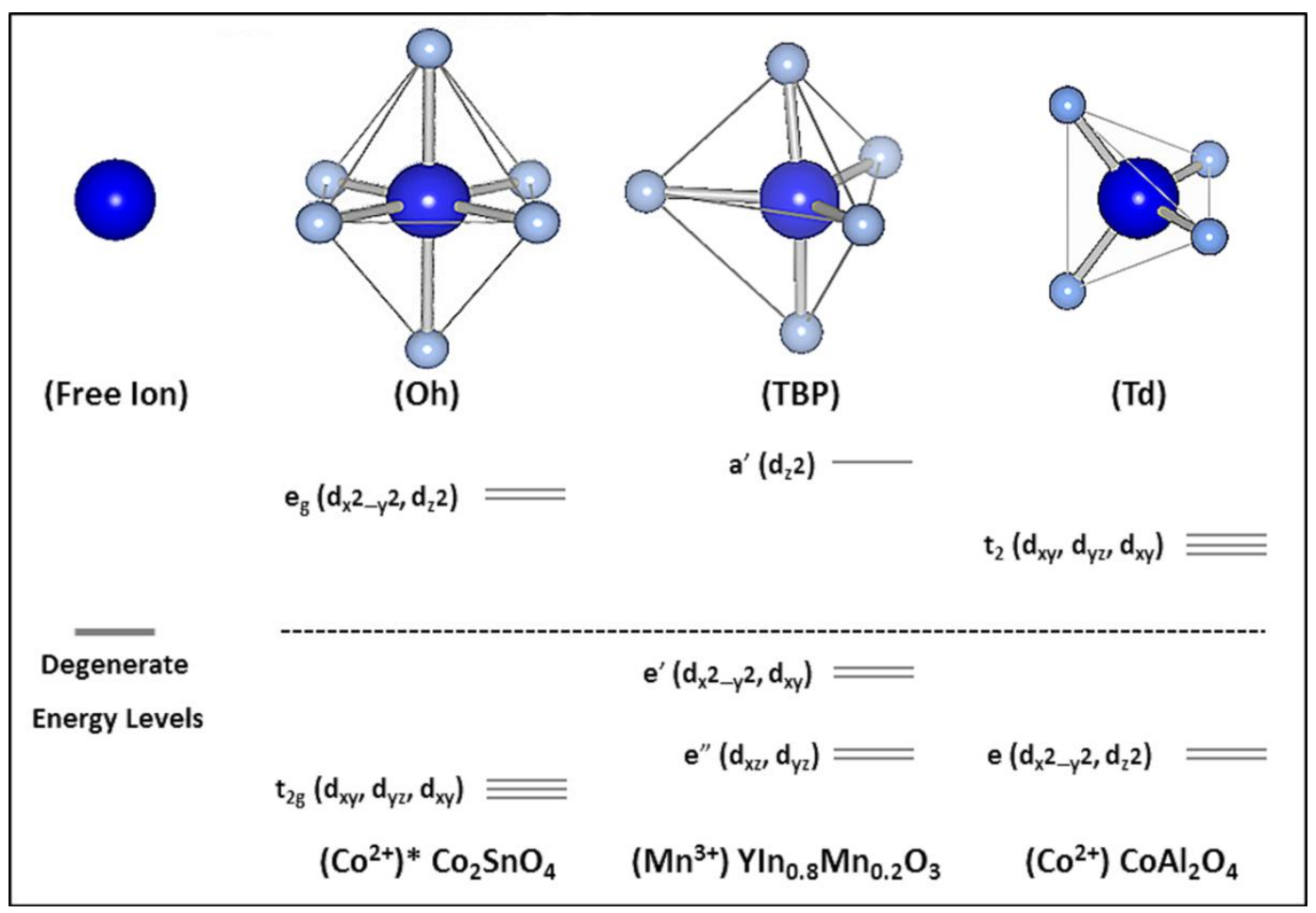

Figure 5. Relative $M O$ splitting levels for octahedral $\left(O_{h}\right)$, trigonal bipyramidal (TBP), and tetrahedral $\left(T_{d}\right)$ coordination environments. ${ }^{*} \mathrm{CO}_{2} \mathrm{SnO}_{4}$ is an inverse spinel in which $\mathrm{Co}^{2+}$ occupies both the $T_{d}$ and $\mathrm{O}_{h}$ coordination environments. 

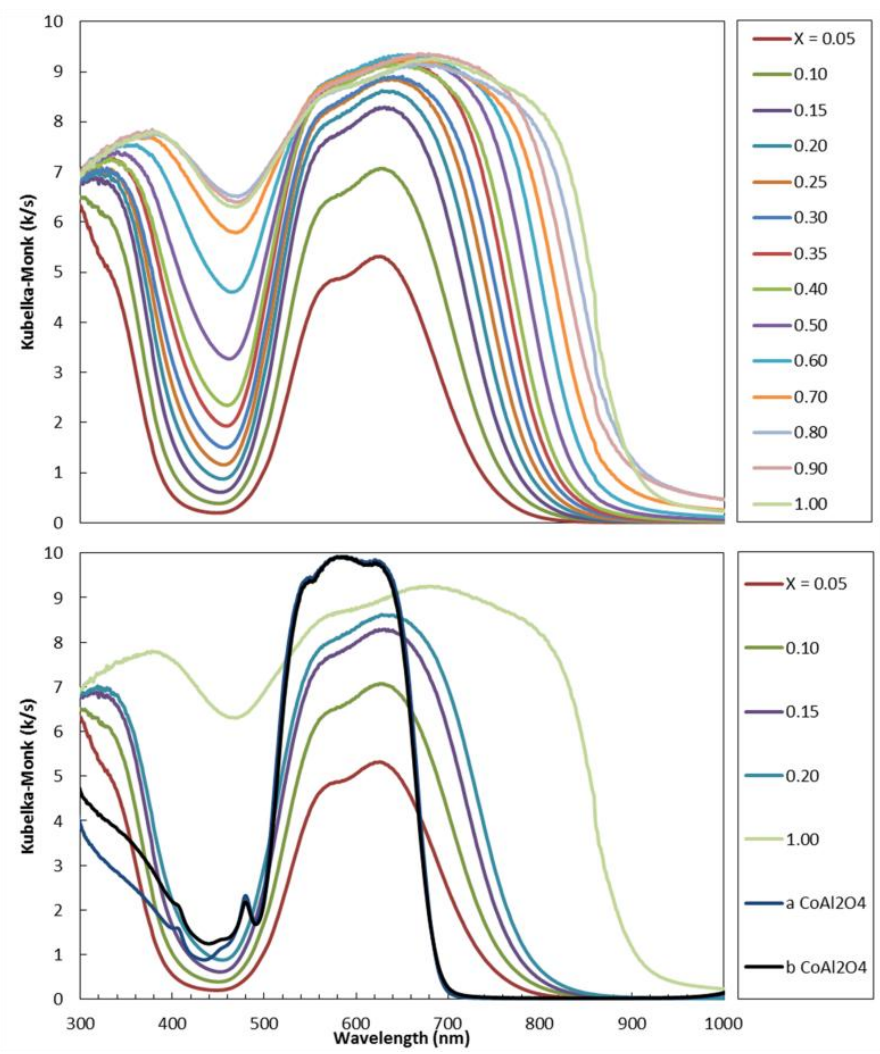

Figure 6. Optical evolution of Kubelka-Monk absorption of pigmented acrylic resin. (Top) Full $\mathrm{YIn}_{1-x} \mathrm{Mn}_{x} \mathrm{O}_{3}$ solid solution. (Bottom) Select $\mathrm{Y} I n_{1-x} \mathrm{Mn}_{x} \mathrm{O}_{3}$ compositions compared to two industrial $\mathrm{CoAl} \mathrm{O}_{4}$ pigments. 
Table 1. Color coordinates calculated using spectral analysis of pigmented acrylic as a masstone.

\begin{tabular}{|c|c|c|c|c|c|c|}
\hline \multirow{2}{*}{ Pigment composition } & \multicolumn{5}{|c|}{ CIE Color Coordinates } & \multirow{2}{*}{$\begin{array}{l}\text { Absorption Minima } \\
\qquad(\mathrm{nm})\end{array}$} \\
\hline & $L^{*}$ & $a^{*}$ & $b^{*}$ & $C^{*}$ & $h^{\circ}$ & \\
\hline${ }^{\mathrm{a}} \mathrm{CoAl}_{2} \mathrm{O}_{4}$ & 32.6 & 12.8 & -40.3 & 42.2 & -72.4 & 435 \\
\hline${ }^{b} \mathrm{CoAl}_{2} \mathrm{O}_{4}$ & 32.8 & 6.9 & -35.0 & 35.7 & -78.8 & 441 \\
\hline $\mathrm{Yln}_{0.95} \mathrm{Mn}_{0.05} \mathrm{O}_{3}$ & 45.4 & 10.9 & -51.0 & 52.2 & -77.9 & 449 \\
\hline $\mathrm{YIn} \mathrm{n}_{0.90} \mathrm{Mn}_{0.10} \mathrm{O}_{3}$ & 40.0 & 11.9 & -47.9 & 49.4 & -76.1 & 451 \\
\hline $\mathrm{Yln}_{0.85} \mathrm{Mn}_{0.15} \mathrm{O}_{3}$ & 36.3 & 12.0 & -44.2 & 45.8 & -74.8 & 453 \\
\hline $\mathrm{YIn}{ }_{0.80} \mathrm{Mn}_{0.20} \mathrm{O}_{3}$ & 34.6 & 9.6 & -38.9 & 40.1 & -76.1 & 455 \\
\hline $\mathrm{YIn}_{0.75} \mathrm{Mn}_{0.25} \mathrm{O}_{3}$ & 33.4 & 7.7 & -34.5 & 35.4 & -77.4 & 455 \\
\hline $\mathrm{YIn}{ }_{0.70} \mathrm{Mn}_{0.30} \mathrm{O}_{3}$ & 32.5 & 5.8 & -30.1 & 30.6 & -79.1 & 458 \\
\hline $\mathrm{YIn}_{0.65} \mathrm{Mn}_{0.35} \mathrm{O}_{3}$ & 31.3 & 4.2 & -25.9 & 26.3 & -80.8 & 459 \\
\hline $\mathrm{Yln}_{0.60} \mathrm{Mn}_{0.40} \mathrm{O}_{3}$ & 30.8 & 2.9 & -22.3 & 22.5 & -82.7 & 459 \\
\hline $\mathrm{YIn}{ }_{0.50} \mathrm{Mn}_{0.50} \mathrm{O}_{3}$ & 29.8 & 0.6 & -16.3 & 16.3 & -87.8 & 462 \\
\hline $\mathrm{YIn}{ }_{0.40} \mathrm{Mn}_{0.60} \mathrm{O}_{3}$ & 28.9 & -0.9 & -10.1 & 10.2 & 84.9 & 465 \\
\hline $\mathrm{Yln}{ }_{0.30} \mathrm{Mn}_{0.70} \mathrm{O}_{3}$ & 28.4 & -1.4 & -6.1 & 6.3 & 77.0 & 468 \\
\hline $\mathrm{YIn}{ }_{0.20} \mathrm{Mn}_{0.80} \mathrm{O}_{3}$ & 28.3 & -1.5 & -3.9 & 4.2 & 69.7 & 469 \\
\hline $\mathrm{Yln}_{0.10} \mathrm{Mn}_{0.90} \mathrm{O}_{3}$ & 28.2 & -1.6 & -4.4 & 4.7 & 70.0 & 470 \\
\hline $\mathrm{YMnO}_{3}$ & 28.4 & -1.5 & -4.4 & 4.7 & 71.3 & 468 \\
\hline
\end{tabular}

Representation of two different $\mathrm{COAl}_{2} \mathrm{O}_{4}$ samples is denoted by superscripts $\boldsymbol{a}$ and $\boldsymbol{b}$. 


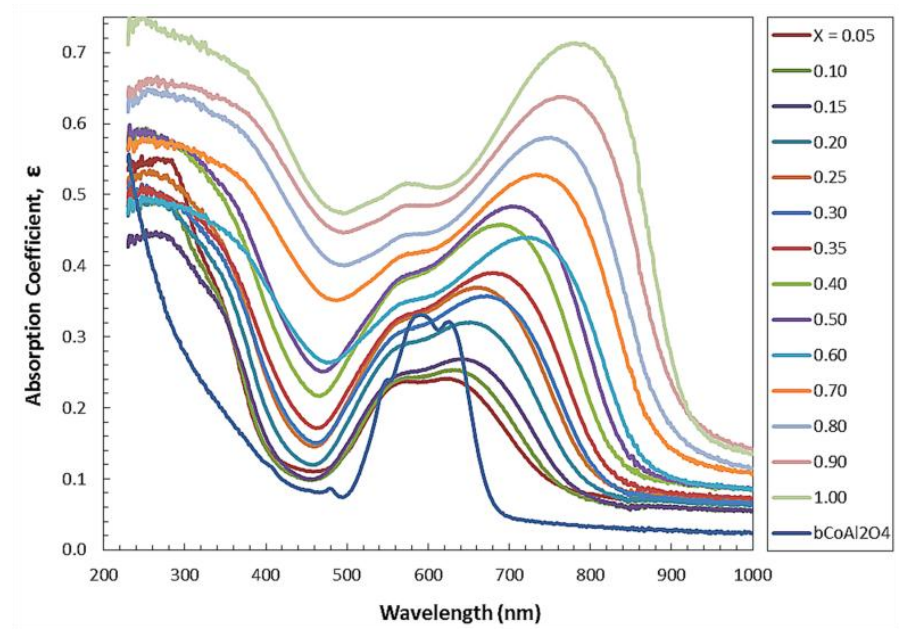

Figure 7. Thin film absorption coefficient of pigmented PVDF resin for the full $\mathrm{YIn}_{1-x} \mathrm{Mn}_{x} \mathrm{O}_{3}$ solid solution and industrial pigment $\mathrm{CoAl}_{2} \mathrm{O}_{4}$. 


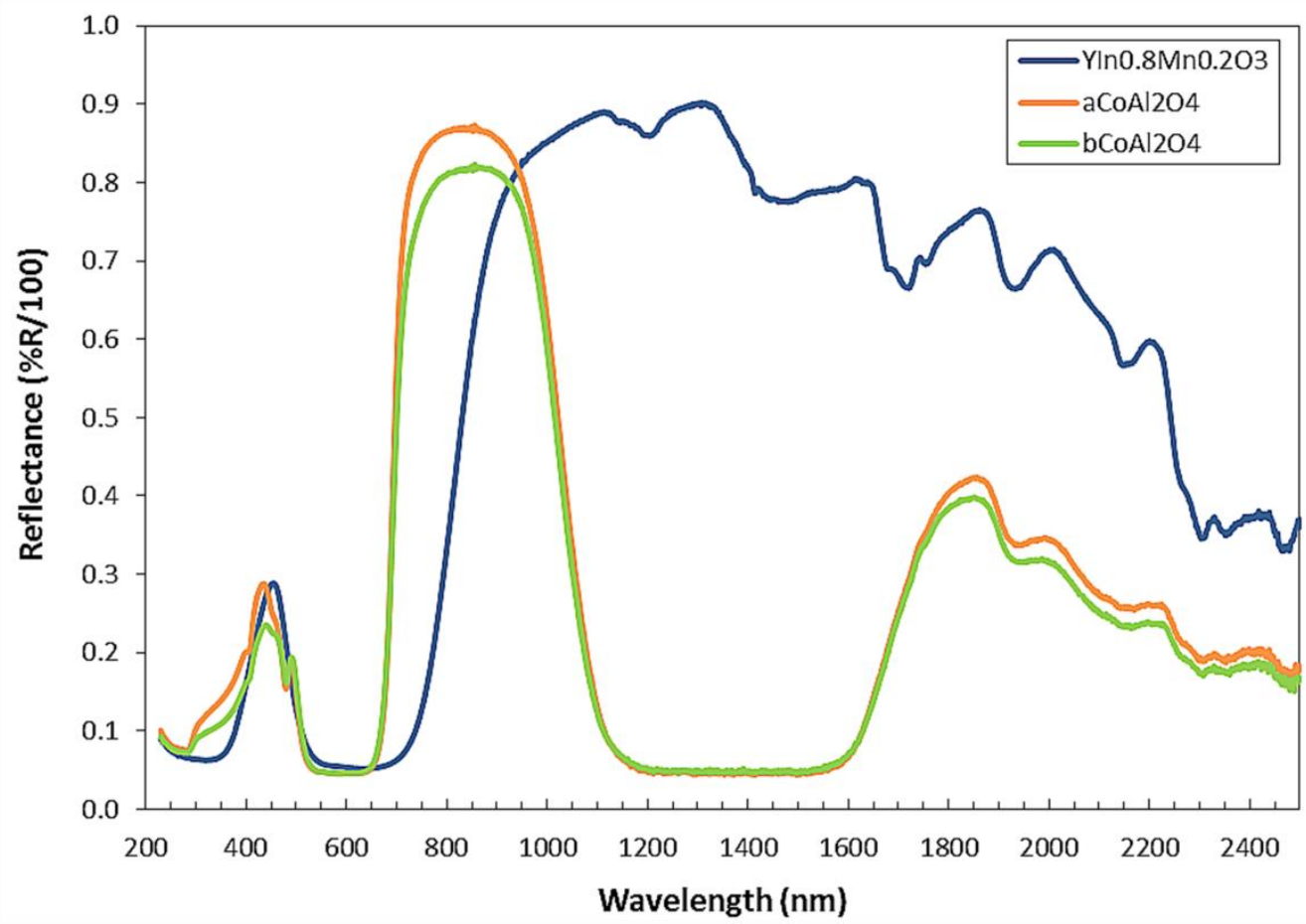

Figure 8. Reflectance spectra for cobalt blue pigments and $\mathrm{YIn}_{0.8} \mathrm{Mn}_{0.2} \mathrm{O}_{3}$ pigmented acrylic resin. 


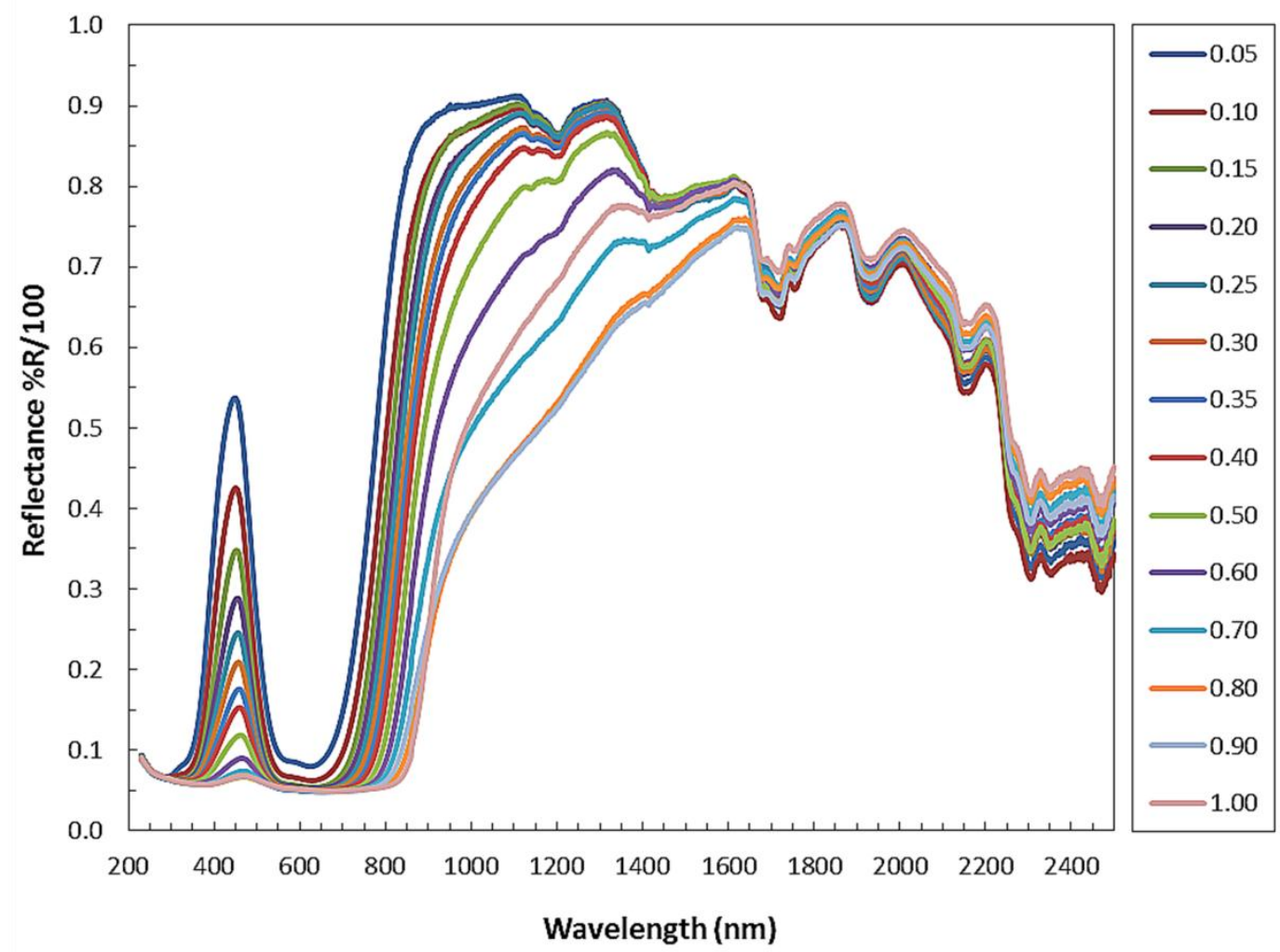

Figure 9. Reflectance spectra for $Y I n_{1-x} \mathrm{Mn}_{x} \mathrm{O}_{3}$ pigmented acrylic resin. 
Table 2. QUV and outdoor weathering of materials in PVDF/Acrylic resin as full masstone and 4:1 tint.

\begin{tabular}{|c|c|c|c|c|c|c|c|c|c|c|c|c|c|c|}
\hline \multirow{2}{*}{$\begin{array}{l}\text { Pigment } \\
\text { Masstone }\end{array}$} & \multicolumn{4}{|c|}{ Initial CIE Lab Color Values } & \multicolumn{5}{|c|}{$\begin{array}{l}\text { QUV 5000hr Exposure } \\
\text { Final CIE Color Value Changes }\end{array}$} & \multicolumn{5}{|c|}{$\begin{array}{l}48 \text { Months Cincinnati Exposure } \\
\text { Final CIE Color Value Changes }\end{array}$} \\
\hline & $\mathrm{L}^{*}$ & $a^{*}$ & $b^{*}$ & $\begin{array}{l}60^{\circ} \\
\text { gloss }\end{array}$ & $\Delta \mathrm{L}^{*}$ & $\Delta \mathrm{a}^{*}$ & $\Delta \mathrm{b}^{*}$ & $\Delta \mathrm{E}^{*}$ & $\begin{array}{l}\Delta 60^{\circ} \\
\text { gloss }\end{array}$ & $\Delta \mathrm{L}^{*}$ & $\Delta a^{*}$ & $\Delta \mathrm{b}^{*}$ & $\Delta \mathrm{E}^{*}$ & $\begin{array}{l}\Delta 60^{\circ} \\
\text { gloss }\end{array}$ \\
\hline${ }^{\mathrm{a}} \mathrm{CoAl}_{2} \mathrm{O}_{4}$ & 36.1 & 11.2 & -48.8 & 25 & -0.2 & 0.9 & -0.7 & 1.1 & 0 & -1.2 & 1.2 & 2.0 & 2.7 & -1 \\
\hline${ }^{\mathrm{a}} \mathrm{CoAl}_{2} \mathrm{O}_{4}$ & 36.1 & 10.9 & -48.6 & 23 & -0.2 & 1.2 & -0.8 & 1.4 & 2 & -0.9 & 1.8 & 2.8 & 3.5 & -1 \\
\hline${ }^{b} \mathrm{CoAl}_{2} \mathrm{O}_{4}$ & 35.8 & 6.7 & -44.3 & 27 & 0.0 & 0.8 & -0.4 & 0.9 & 0 & -0.5 & 0.0 & 0.6 & 0.8 & 3 \\
\hline${ }^{\mathrm{b}} \mathrm{CoAl} \mathrm{O}_{2} \mathrm{O}_{4}$ & 36.0 & 6.4 & -44.2 & 26 & -0.1 & 1.0 & -0.6 & 1.2 & 4 & -0.5 & 0.0 & 0.6 & 0.8 & 1 \\
\hline $\mathrm{Yln}_{0.8} \mathrm{Mn}_{0.2} \mathrm{O}_{3}$ & 34.8 & 11.7 & -45.2 & 55 & 0.0 & 0.3 & -0.4 & 0.5 & -1 & 0.1 & -0.5 & 1.1 & 1.2 & 2 \\
\hline $\mathrm{YIn}_{0.8} \mathrm{Mn}_{0.2} \mathrm{O}_{3}$ & 34.7 & 11.6 & -45.1 & 55 & 0.1 & 0.4 & -0.4 & 0.5 & -1 & 0.2 & -0.5 & 1.2 & 1.3 & 2 \\
\hline $4: 1$ Tint & $L^{*}$ & $a^{*}$ & $b^{*}$ & $\begin{array}{l}60^{\circ} \\
\text { gloss }\end{array}$ & $\Delta \mathrm{L}^{*}$ & $\Delta \mathrm{a}^{*}$ & $\Delta \mathrm{b}^{*}$ & $\Delta \mathrm{E}^{*}$ & $\begin{array}{l}\Delta 60^{\circ} \\
\text { gloss }\end{array}$ & $\Delta \mathrm{L}^{*}$ & $\Delta \mathrm{a}^{*}$ & $\Delta \mathrm{b}^{*}$ & $\Delta \mathrm{E}^{*}$ & $\begin{array}{l}\Delta 60^{\circ} \\
\text { gloss }\end{array}$ \\
\hline${ }^{\mathrm{a}} \mathrm{CoAl}_{2} \mathrm{O}_{4}$ & 77.7 & -7.3 & -25.3 & 64 & -0.2 & 0.6 & -0.9 & 1.1 & 4 & -0.5 & 0.1 & -0.3 & 0.5 & -1 \\
\hline${ }^{\mathrm{a}} \mathrm{CoAl}_{2} \mathrm{O}_{4}$ & 77.7 & -7.4 & -24.9 & 64 & -0.3 & 0.7 & -1.2 & 1.4 & 3 & -0.4 & 0.1 & -0.3 & 0.5 & -1 \\
\hline${ }^{b} \mathrm{CoAl}_{2} \mathrm{O}_{4}$ & 77.6 & -7.6 & -24.4 & 63 & -0.3 & 0.4 & -0.7 & 0.8 & 2 & -0.9 & 0.3 & 0.3 & 1.0 & 3 \\
\hline${ }^{\mathrm{b}} \mathrm{CoAl}_{2} \mathrm{O}_{4}$ & 77.6 & -7.7 & -24.2 & 63 & -0.3 & 0.5 & -0.8 & 1.0 & 2 & -0.7 & 0.2 & 0.4 & 0.8 & 2 \\
\hline $\mathrm{YIn}_{0.8} \mathrm{Mn}_{0.2} \mathrm{O}_{3}$ & 77.6 & -2.7 & -21.4 & 69 & 0.0 & 0.1 & -0.2 & 0.2 & 0 & -0.5 & 0.1 & 0.9 & 1.0 & 3 \\
\hline $\mathrm{Yln}_{0.8} \mathrm{Mn}_{0.2} \mathrm{O}_{3}$ & 77.6 & -2.6 & -21.5 & 66 & 0.0 & 0.1 & -0.1 & 0.2 & 4 & -0.6 & 0.0 & 1.0 & 1.2 & 1 \\
\hline
\end{tabular}

Representation of two different $\mathrm{CoAl}_{2} \mathrm{O}_{4}$ samples is denoted by superscripts $\boldsymbol{a}$ and $\boldsymbol{b}$. A replicate of each sample was analyzed to show variation due to sample preparation. 
Table 3. Solar reflectance percentages calculated from spectral analysis of pigmented acrylic resin as a masstone

\begin{tabular}{|c|c|c|c|c|}
\hline \multirow{2}{*}{ Pigment composition } & \multicolumn{4}{|c|}{ Solar reflectance (\%R) } \\
\hline & TSR & UV & VIS & NIR \\
\hline${ }^{\mathrm{a}} \mathrm{CoAl} \mathrm{O}_{4}$ & 34.1 & 15.7 & 27.3 & 42.3 \\
\hline${ }^{\mathrm{b}} \mathrm{CoAl}{ }_{2} \mathrm{O}_{4}$ & 31.8 & 12.3 & 25.1 & 39.9 \\
\hline $\mathrm{Yln}_{0.95} \mathrm{Mn}_{0.05} \mathrm{O}_{3}$ & 50.3 & 17.5 & 23.0 & 81.0 \\
\hline $\mathrm{Yln}_{0.90} \mathrm{Mn}_{0.10} \mathrm{O}_{3}$ & 45.4 & 13.0 & 17.1 & 77.2 \\
\hline $\mathrm{Yln}_{0.85} \mathrm{Mn}_{0.15} \mathrm{O}_{3}$ & 43.1 & 10.2 & 13.4 & 76.3 \\
\hline $\mathrm{YIn}_{0.80} \mathrm{Mn}_{0.20} \mathrm{O}_{3}$ & 40.9 & 9.1 & 11.4 & 73.8 \\
\hline $\mathrm{Yln}_{0.75} \mathrm{Mn}_{0.25} \mathrm{O}_{3}$ & 39.6 & 8.3 & 10.0 & 72.6 \\
\hline $\mathrm{YIn}_{0.70} \mathrm{Mn}_{0.30} \mathrm{O}_{3}$ & 37.9 & 7.9 & 9.0 & 70.0 \\
\hline $\mathrm{Yln}_{0.65} \mathrm{Mn}_{0.35} \mathrm{O}_{3}$ & 36.7 & 7.2 & 8.0 & 68.6 \\
\hline $\mathrm{Yln}_{0.60} \mathrm{Mn}_{0.40} \mathrm{O}_{3}$ & 35.5 & 6.9 & 7.5 & 66.7 \\
\hline $\mathrm{Yln}_{0.50} \mathrm{Mn}_{0.50} \mathrm{O}_{3}$ & 33.1 & 6.4 & 6.6 & 62.5 \\
\hline $\mathrm{Yln}_{0.40} \mathrm{Mn}_{0.60} \mathrm{O}_{3}$ & 30.2 & 6.0 & 6.0 & 57.2 \\
\hline $\mathrm{YIn}_{0.30} \mathrm{Mn}_{0.70} \mathrm{O}_{3}$ & 26.5 & 5.8 & 5.6 & 49.8 \\
\hline $\mathrm{Yln}_{0.20} \mathrm{Mn}_{0.80} \mathrm{O}_{3}$ & 23.2 & 5.8 & 5.5 & 42.9 \\
\hline $\mathrm{Yln}_{0.10} \mathrm{Mn}_{0.90} \mathrm{O}_{3}$ & 23.2 & 5.8 & 5.5 & 42.9 \\
\hline $\mathrm{YMnO}_{3}$ & 26.5 & 5.8 & 5.5 & 49.8 \\
\hline
\end{tabular}

Representation of two different $\mathrm{COAl}_{2} \mathrm{O}_{4}$ samples is denoted by superscripts $\boldsymbol{a}$ and $\boldsymbol{b}$. 
Table 4. Solar reflectance percentages calculated from spectral analysis of pigmented Polyvinyl Chloride (PVC) resin as a masstone at a $5 \%$ pigment loading.

\begin{tabular}{|c|c|c|c|c|c|c|c|c|}
\hline \multirow{2}{*}{$\begin{array}{l}\text { Pigment } \\
\text { composition }\end{array}$} & \multicolumn{3}{|c|}{ CIE Lab Color Values (PVC) } & \multicolumn{4}{|c|}{ Solar reflectance (\%R) (PVC) } & \multirow{2}{*}{\begin{tabular}{|c|}
$\begin{array}{c}\text { Heat Build } \\
\text { Up }\end{array}$ \\
HBU $\left({ }^{\circ} \mathrm{C}\right)$
\end{tabular}} \\
\hline & $L^{*}$ & $a^{*}$ & $b^{*}$ & TSR & UV & VIS & NIR & \\
\hline Carbon Black & 25.3 & -0.1 & -0.9 & 4.6 & 5.0 & 4.5 & 4.6 & 42.0 \\
\hline${ }^{\mathrm{a}} \mathrm{CoAl} \mathrm{O}_{4}$ & 36.1 & 7.7 & -39.8 & 27.2 & 19.7 & 17.4 & 34.9 & 37.5 \\
\hline${ }^{b} \mathrm{CoAl}_{2} \mathrm{O}_{4}$ & 37.1 & 5.2 & -38.0 & 28.4 & 18.4 & 18.3 & 36.5 & 37.0 \\
\hline $\mathrm{Yln}_{0.95} \mathrm{Mn}_{0.05} \mathrm{O}_{3}$ & 47.0 & 8.6 & -49.7 & 44.3 & 22.7 & 21.5 & 62.5 & 26.9 \\
\hline $\mathrm{Yln}_{0.90} \mathrm{Mn}_{0.10} \mathrm{O}_{3}$ & 41.8 & 10.8 & -48.8 & 41.0 & 17.4 & 16.8 & 60.4 & 26.9 \\
\hline $\mathrm{Yln}_{0.85} \mathrm{Mn}_{0.15} \mathrm{O}_{3}$ & 38.4 & 11.6 & -46.0 & 38.6 & 14.2 & 13.8 & 58.4 & 27.1 \\
\hline $\mathrm{Yln}_{0.80} \mathrm{Mn}_{0.20} \mathrm{O}_{3}$ & 36.1 & 10.2 & -42.4 & 36.4 & 11.9 & 11.9 & 56.0 & 27.4 \\
\hline $\mathrm{Yln}_{0.75} \mathrm{Mn}_{0.25} \mathrm{O}_{3}$ & 35.2 & 8.4 & -37.8 & 35.4 & 10.9 & 10.8 & 55.1 & 27.3 \\
\hline $\mathrm{Yln}_{0.70} \mathrm{Mn}_{0.30} \mathrm{O}_{3}$ & 33.6 & 6.1 & -32.9 & 33.6 & 9.6 & 9.5 & 52.8 & 27.7 \\
\hline $\mathrm{Yln}_{0.65} \mathrm{Mn}_{0.35} \mathrm{O}_{3}$ & 32.7 & 4.7 & -29.9 & 33.5 & 8.9 & 8.8 & 53.2 & 27.3 \\
\hline $\mathrm{Yln}_{0.60} \mathrm{Mn}_{0.40} \mathrm{O}_{3}$ & 31.9 & 3.1 & -25.5 & 32.4 & 8.2 & 8.1 & 51.8 & 27.5 \\
\hline $\mathrm{Yln}_{0.50} \mathrm{Mn}_{0.50} \mathrm{O}_{3}$ & 31.2 & 0.5 & -19.7 & 31.2 & 7.5 & 7.4 & 50.3 & 27.5 \\
\hline $\mathrm{YIn}_{0.40} \mathrm{Mn}_{0.60} \mathrm{O}_{3}$ & 29.5 & -1.2 & -12.5 & 29.1 & 6.4 & 6.3 & 47.3 & 27.8 \\
\hline $\mathrm{YIn}_{0.30} \mathrm{Mn}_{0.70} \mathrm{O}_{3}$ & 30.0 & -1.7 & -7.1 & 26.1 & 6.6 & 6.4 & 41.8 & 29.0 \\
\hline $\mathrm{YIn}_{0.20} \mathrm{Mn}_{0.80} \mathrm{O}_{3}$ & 30.3 & -2.0 & -5.0 & 24.5 & 6.3 & 6.4 & 38.9 & 29.6 \\
\hline $\mathrm{Yln}_{0.10} \mathrm{Mn}_{0.90} \mathrm{O}_{3}$ & 27.9 & -1.9 & -4.7 & 23.1 & 5.7 & 5.4 & 37.1 & 29.9 \\
\hline $\mathrm{YMnO}_{3}$ & 28.7 & -1.9 & -5.6 & 27.4 & 5.9 & 5.7 & 44.7 & 27.6 \\
\hline
\end{tabular}

Representation of two different $\mathrm{COAl}_{2} \mathrm{O}_{4}$ samples is denoted by superscripts $\boldsymbol{a}$ and $\boldsymbol{b}$. 
Figure 1. Solar spectral irradiance based on combined direct and circumsolar effects from ASTM G173-03 reference spectra derived from the Simple Model of the Atmospheric Radiative Transfer of Sunshine, SMARTS [14]. Shading of spectral regions has been added.

Figure 2. Normalized powder $\mathrm{x}$-ray diffraction patterns of the $\mathrm{YInO}_{3}-\mathrm{YMnO}_{3}$ miscibility range. The inset shows the (002) and (102) peaks magnified.

Figure 3. Normalized particle size distribution of $\mathrm{YIn}_{1-x} \mathrm{Mn}_{x} \mathrm{O}_{3}, x=0.05-1.0$, and commercial $\mathrm{CoAl}_{2} \mathrm{O}_{4}$ pigments.

Figure 4. SEM images of $Y I n_{1-x} M n_{x} O_{3}$, before (a-c) and after (d-f) milling where $x=0.2,0.5$, and 1.0, respectively.

Figure 5. Relative $M O$ splitting levels for octahedral $\left(O_{h}\right)$, trigonal bipyramidal (TBP), and tetrahedral $\left(T_{d}\right)$ coordination environments. ${ }^{*} \mathrm{CO}_{2} \mathrm{SnO}_{4}$ is an inverse spinel in which $\mathrm{Co}^{2+}$ occupies both the $T_{d}$ and $O_{h}$ coordination environments.

Figure 6. Optical evolution of Kubelka-Monk absorption of pigmented acrylic resin. (Top) Full $\mathrm{YIn}_{1-\mathrm{x}} \mathrm{Mn}_{\mathrm{x}} \mathrm{O}_{3}$ solid solution. (Bottom) Select $\mathrm{YIn}{ }_{1-x} \mathrm{Mn}_{x} \mathrm{O}_{3}$ compositions compared to two industrial $\mathrm{CoAl}{ }_{2} \mathrm{O}_{4}$ pigments.

Figure 7. Thin film absorption coefficient of pigmented PVDF resin for the full $\mathrm{YIn}_{1-x} M n_{x} \mathrm{O}_{3}$ solid solution and industrial pigment $\mathrm{CoAl}_{2} \mathrm{O}_{4}$.

Figure 8. Reflectance spectra for cobalt blue pigments and $\mathrm{YIn}_{0.8} \mathrm{Mn}_{0.2} \mathrm{O}_{3}$ pigmented acrylic resin.

Figure 9. Reflectance spectra for $\mathrm{Y} / n_{1-x} \mathrm{Mn}_{x} \mathrm{O}_{3}$ pigmented acrylic resin.

Table 1. Color coordinates calculated using spectral analysis of pigmented acrylic as a masstone. Representation of two different $\mathrm{COAl}_{2} \mathrm{O}_{4}$ samples is denoted by superscripts $\boldsymbol{a}$ and $\boldsymbol{b}$.

Table 2. QUV and outdoor weathering of materials in PVDF/Acrylic resin as full masstone and 4:1 tint. Representation of two different $\mathrm{COAl}_{2} \mathrm{O}_{4}$ samples is denoted by superscripts $\boldsymbol{a}$ and $\boldsymbol{b}$. $A$ replicate of each sample was analyzed to show variation due to sample preparation.

Table 3. Solar reflectance percentages calculated from spectral analysis of pigmented acrylic resin as a masstone. Representation of two different $\mathrm{CoAl}_{2} \mathrm{O}_{4}$ samples is denoted by superscripts $\boldsymbol{a}$ and $\boldsymbol{b}$.

Table 4. Solar reflectance percentages calculated from spectral analysis of pigmented Polyvinyl Chloride (PVC) resin as a masstone at a $5 \%$ pigment loading.

Representation of two different $\mathrm{COAl}_{2} \mathrm{O}_{4}$ samples is denoted by superscripts $\boldsymbol{a}$ and $\boldsymbol{b}$. 